EESTI NSV TEADUSTE AKADEEMIA TOIMETISED, 26. KOIDE

FOOSIKA * MATEMAATIKA. 1977, NR. 1

ИЗВЕСТИЯ АКАДЕМИИ НАУК ЭСТОНСКОН ССР. ТОМ 26 ФИЗИҚА * МАТЕМАТИҚА, 1977, № 1

\title{
ОПРЕДЕЛЕНИЕ ПАРАМЕТРОВ ТРИПЛЕТНОГО СОСТОЯНИЯ ИЗ КИНЕТИКИ ФЛУОРЕСЦЕНЦИИ
}

\author{
R. AVARMAA, K. MAURING. TRIPLETTSEISUNDI PARAMEETRITE MAARAMINE FLUORES- \\ TSENTSI KINEETIKA ALUSEL \\ R. AVARMAA, K. MAURING. FLUORESCENCE KINETICS DETECTION OF TRIPLET STATE \\ PARAMETERS
}

В целях изучения триплетных состояний молекул наряду с методами, исследующими их фосфоресценцию, применяются некоторые косвенные и комбинированные методы, например, $T-T$-поглощение, микроволновой оптический двойной резонанс и др. $\left[{ }^{1-3}\right]$. Косвенные методы особенно полезны в тех случаях, когда фосфоресценция потушена или находится в неудобной для наблюдения области спектра. К числу соединений, фосфоресценция которых слаба и находится в далекой красной области, относятся, в частности, хлорофиллоподобные молекулы $\left[{ }^{4,5}\right]$.

Изучение триплетного состояния хлорофилла путем селективной накачки было предпринято в $\left[{ }^{6,7}\right]$. В настоящем сообщении мы продолжаем эти исследования способом, заключающимся в онределении кривых падения во времени интенсивности флуоресценции за счет заселения триплета.

Объектами эксперимента служили хлорофиллоподобные и некоторые ароматические молекулы, замороженные в органических растворителях. Измерения проводились при 77 и $4,2 \mathrm{~K}$. Возбуждение осуществлялось $\mathrm{He}-\mathrm{Ne}(6328 \AA)$ или $\mathrm{Cd}(4416 \AA)$ лазером. Возбуждающий луч преобразовывался с помощью дискового модулятора в прямоугольные импульсы и фокусировался на объект. Люминесценция регистрировалась спектрометром ДФС-24 и фотоумножителем ФЭУ-79 в режиме счета фотонов. Временной ход сигнала записывался на анализаторе LP-4840 («Нокиа» Финляндия) при накоплении от $10^{4}$ до $10^{5}$ циклов.

У всех изученных нами молекул наблюдалось падение интенсивности флуоресценции за период постоянного возбуждения, причем изменение интенсивности $\delta I$, отнесенное к ее стационарному значению, составляло от 1 до $120 \%$. Наибольшие $\delta I$ были получены для хлорофиллоподобных молекул (рисунок), имеющих, как известно, высокий выход триплета $\left[{ }^{4}\right]$.

Дополнительными экспериментами было проверено, что наблюдаемый эффект падения интенсивности флуоресценции не связан с посторонними факторами, например, с изменением свойств матрицы-растворителя под влиянием возбуждения высокой интенсивности. Правильность интерпретации результатов подтверждает совпадение постоянных 


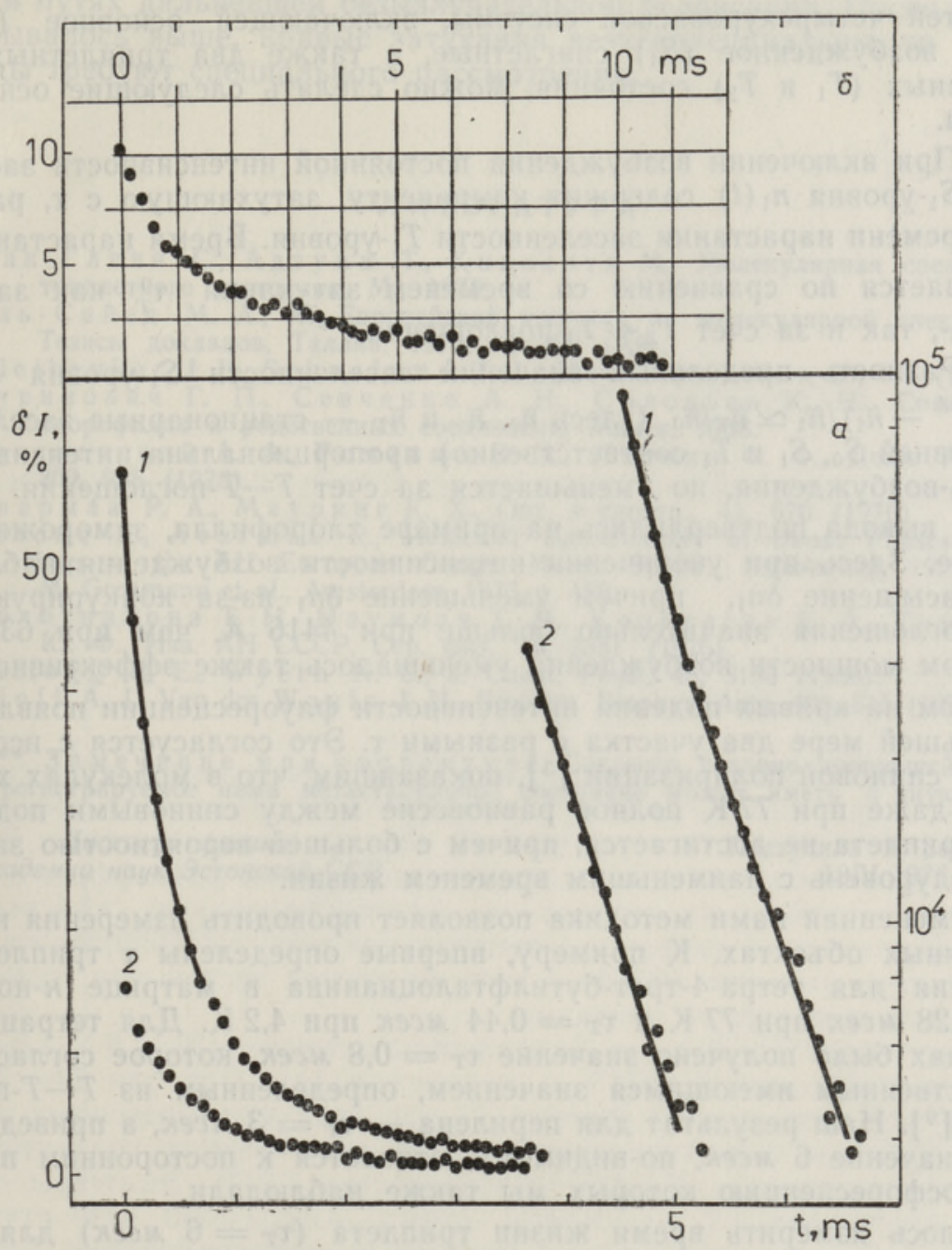

Изменение во времени интенсивности флуоресценции $\delta I$ при возбуждении прямоугольными импульсами лазера.

$a-$ Хлорофилл $a$ в эфире (1) при возбуждении $\lambda_{e}=6328 \AA$ и регистрации флуоресценции $\lambda_{r}=6700 \AA$; тетрацен в $\lambda_{e}=4416 \AA$ и $\lambda_{r}=4752 \AA$. Справа те же кривые представлены в логарифмическом масштабе $\delta I$.

6 - Хлорофилл в замороженном листе; $\lambda_{e}=6328 \AA, \lambda_{\tau}=6850 \AA$, $T=77 \mathrm{~K}$.

времени $\left(\tau_{T}=2\right.$ мсек), определенных из затухания фосфоресценции и кинетики флуоресценции в случае диацетила в этаноле. *

Обратимся теперь к кинетическим уравнениям. В случае малого спин-орбитального расщепления и не очень низкой температуры три подуровня триплетного состояния находятся в тепловом равновесии и, следовательно, их можно трактовать как одно состояние с усредненным временем жизни $\left[{ }^{1,2}\right]$.

Из проведенного нами приближенного рассмотрения кинетики засе-

* У остальных молекул в рабочей области спектрометра (400-850 нм) фосфоресценция не наблюдалась. 
ленностей четырехуровневой системы, включающей основное $\left(S_{0}\right)$ и первое возбужденное $\left(S_{1}\right)$ синглетные, а также два триплетных возбужденных ( $T_{1}$ и $\left.T_{2}\right)$ состояния, можно сделать следующие основные выводы.

1. При включении возбуждения постоянной интенсивности заселенность $S_{1}$-уровня $n_{1}(t)$ содержит компоненту, затухающую с $\tau$, равным $\tau_{T}^{*}$ - времени нарастания заселенности $T_{1}$-уровня. Время нарастания $\tau_{T}^{*}$ уменьшается по сравнению со временем затухания $\tau_{T}^{0}$ как за счет $S_{1} \leftarrow S_{0^{-}}$, так и за счет $T_{2} \leftarrow T_{1}$-поглощения. **

2. Разность предельных значений заселенности $S_{1}$-уровня $\delta n_{1} \equiv$ $\equiv\left(n_{1}^{\max }-\tilde{n}_{1}\right) / \tilde{n}_{1} \simeq \tilde{n}_{T} / \tilde{n}_{0}$ (здесь $\tilde{n}_{0}, \tilde{n}_{1}$ и $\tilde{n}_{T}-$ стационарные заселенности уровней $S_{0}, S_{1}$ и $T_{1}$ соответственно) пропорциональна интенсивности $S_{1} \leftarrow S_{0}$-возбуждения, но уменьшается за счет $T-T$-поглощения.

Оба вывода подтвердились на примере хлорофилла, замороженного в эфире. Здесь при увеличении интенсивности возбуждения наблюдалось насыщение $\delta n_{1}$, причем уменьшение $\delta n_{1}$ из-за конкурирующего $T-T$-поглощения значительно больше при $4416 \AA$, чем при $6328 \AA$. С ростом мощности возбуждения уменьшалось также эффективное $\tau_{T}^{*}$. При этом на кривых падения интенсивности флуоресценции появлялось по меньшей мере два участка с разными $\tau$. Это согласуется с исследованием спиновой поляризации $\left[{ }^{3}\right]$, показавшим, что в молекулах хлорофилла даже при $77 \mathrm{~K}$ полное равновесие между спиновыми подуровнями триплета не достигается, причем с большей вероятностью заселяется подуровень с наименьшим временем жизни.

Примененная нами методика позволяет проводить измерения на непрозрачных объектах. К примеру, впервые определены $\tau$ триплетного состояния для тетра-4-трет-бутилфталоцианина в матрице $H$-нонана: $\tau_{T}=0,28$ мсек при $77 \mathrm{~K}$ и $\tau_{T}=0,44$ мсек при $4,2 \mathrm{~K}$. Для тетрацена в $\mu$-алканах было получено значение $\tau_{T}=0,8$ мсек, которое согласуется с единственным имеющимся значением, определенным из $T$ - $T$-поглощения $\left[{ }^{9}\right]$. Наш результат для перилена $-\tau_{T}=3$ мсек, а приведенное в $\left[{ }^{9}\right]$ значение 6 мсек, по-видимому, относится к посторонним примесям, фосфоресценцию которых мы также наблюдали.

Удалось измерить время жизни триплета $\left(\tau_{T}=6\right.$ мсек) для хлорофилла (регистрация флуоресценции при $6850 \AA$ ) в замороженном зеленом листе при $77 \mathrm{~K}$ (рисунок). ***

В случае неоднородных систем предложенный нами метод позволяет обнаруживать различное происхождение отдельных полос или линий. Именно таким путем мы установили, что разные дополнительные максимумы, наблюдаемые в спектре люминесценции хлорофилла и некоторыми авторами интерпретируемые как горячие полосы, суть излучение посторонних примесей, так как параметры триплетного состояния для них заметно различаются.

Данный метод наряду с отмеченными достоинствами имеет и свой недостаток: кривые затухания наблюдаются на фоне стационарной флуоресценции, которая дает тем больший вклад в шумы суммарного сигнала, чем меньше предельная заселенность триплета.

В случае хлорофиллоподобных молекул, когда легко достигаются высокие заселенности триплета, из кинетики флуоресценции в принципе можно получить информацию также о процессах $T$ - $T$-поглоще-

** В [8] отмечалось уменьшение $\tau_{T}^{*}$ за счет $T-T$-поглощения. 
ния и путях дальнейшей безызлучательной релаксации. Поскольку, как указывалось выше, кривые затухания неэкспоненциальны, то эти проблемы требуют специального рассмотрения.

\section{ЛИ Т Е Р А Т Р А}

1. Мак-Глинн С., Адз уми Т., Киносита М., Молекулярная спектроскопия триплетного состояния, М., 1972.

2. Эль-С а й ед M. А., ХІ Европейский конгресс по молекулярной спектроскопии, Тезисы докладов, Таллин, 1973, № 300 (А9).

3. Kleibeuker J. F., S cha af sma T. J., Chem. Phys. Letters, 29, 116 (1974).

4. Гуриинович Г. П., Севченко А. Н., Соловьев К. Н., Спектроскопия хлорофилла и родственных соединений, Минск, 1968.

5. К раснов ский А. А., Ром анюк В. А., Литвин Ф. Ф., Докл. АН СССР, 209, 965 (1973)

6. Ав а рм а а Р. А., М а урин г К. Х., Опт. и спектр., 41, 670 (1976).

7. Rebane K., Avarmaa R., Molecular Spectroscopy of Dense Phases. Proceedings of the XII European Congr. Molec. Spectr., Strasbourg, 1975. Ed. by M. Grosmann et al., Amsterdam, 1976, p. 459.

8. Болотникова Т. Н., Н аумова Т. М., Коротаева Е. А., Тия офеева Ю. Ф., Изв. АН СССР, Сер. физ., 39, 2331 (1975).

9. Kellog g R. E., W y e th N. C., J. Chem. Phys., 45, 3156 (1966).

10. Hof f A. J., Van der W a ls J. H., Biochim. Biophys. Acta, 423, 615 (1976).

З а мечани е при корректуре. Согласно недавно появившейся работе $\left[{ }^{10}\right]$, регистрируемое нами метастабильное состояние может иметь и иную природу.

\section{Институт физики Академии наук Эстонской ССР}

Поступила в редакцию $12 / \mathrm{V} 1976$ 